\title{
Cloning, mutation and distribution of a putative lipopolysaccharide biosynthesis locus in Campylobacter jejuni
}

\author{
Anne C. Wood, † Neil J. Oldfield, Clíona A. O’Dwyer \\ and Julian M. Ketley \\ Author for correspondence: Julian M. Ketley. Tel: +44116252 3434. Fax: +441162523378. \\ e-mail: ket@le.ac.uk
}

Department of Genetics, University of Leicester, University Road, Leicester LE1 7RH, UK

\begin{abstract}
A region encoding ORFs with homology to known lipopolysaccharide (LPS) biosynthesis genes was isolated from two strains of Campylobacter jejuni. One of the strains produces LPS, but the second strain is reported to produce only lipooligosaccharide (LOS) and therefore lacks the O-chain. The two strains shared six predicted ORFs, but an additional ORF, orfE, of unknown function was identified in the LOS-producing strain. Mutation of the shared wbeE ( $\mathrm{fbE}$ ) homologue (orff) or deletion of five of the seven genes reduced core reactivity with specific antiserum without affecting 0-chain production. Mutation of either the CapD homologue (orfG) or the unique orfE had no detectable effect on LOS or LPS production. The presence or absence of orfE in $\mathbf{3 6}$ isolates of C. jejuni did not correlate with LOS/LPS phenotype or serotype. However, after insertion of orfE into a LPS-producing orfE-negative strain the O-chain ladder was no longer detectable on Western blots. We were not able to disrupt the wbaP ( $r f b P$ ) homologue (orfC) in C. jejuni.
\end{abstract}

Keywords: Campylobacter, lipopolysaccharide, genetics, distribution, mutation

\section{INTRODUCTION}

Campylobacter jejuni is the most common cause of foodborne gastroenteritis in the UK (Ketley, 1997); there is also evidence for its involvement in the aetiology of a significant proportion of cases of the neurological disorder Guillain-Barré Syndrome (GBS) (Schwerer et al., 1995; Salloway et al., 1996; Mishu \& Blaser, 1993; Moran et al., 1996). Lipopolysaccharide (LPS) and lipooligosaccharide (LOS) constituents of the outer membrane of Gram-negative organisms have been shown to be important virulence factors during bacterial infection conferring, amongst other things, serum resistance, antibiotic resistance and endotoxic properties on the bacterium (Rietschel et al., 1994). The Penner

†Present address: The Wellcome Trust, 183 Euston Road, London NW1 2BE, UK.

‡ Present address: Microscience Ltd, Dept of Infectious Diseases, Imperial College School of Medicine at The Hammersmith Campus, Du Cane Road, London W12 ONN, UK.

Abbreviations: CAT, chloramphenicol acetyl transferase; GBS, GuillainBarré Syndrome; LPS, lipopolysaccharide; LOS, lipooligosaccharide.

The GenBank/EMBLDDBJ accession numbers for the C. jejuni NCTC 11168 and C. jejuni NCTC 11351 clones reported in this paper are AF001497 and AF001498, respectively. serotyping system (Preston \& Penner, 1987; Penner et al., 1983) of C. jejuni is based upon heat-stable antigens, presumed to be LPS/LOS. C. jejuni LPS/LOS are also of interest in terms of their potential adherent properties (McSweegan \& Walker, 1986) and involvement in the aetiology of GBS (Schwerer et al., 1995; Salloway et al., 1996; Mishu \& Blaser, 1993; Moran et al., 1996).

LPS is composed of three regions, lipid A, a core oligosaccharide and an $\mathrm{O}$-chain consisting of repeating oligosaccharide units; LOS lacks the O-chain (Rietschel et al., 1994). C. jejuni is capable of producing LOS and LPS with remarkably variable and unusual core sugars (Moran, 1995) and several of these structures have been elucidated (Aspinall et al., 1992, 1993a, b, 1994, 1995; Moran et al., 1991a, b; Moran \& O'Malley, 1995; Salloway et al., 1996). In this paper we report the isolation and analysis of part of a putative chromosomal LPS biosynthesis locus from two strains of differing serotypes of C. jejuni. In addition, we report the distribution and gene content of the locus in 36 strains of C. jejuni from a range of different serotypes.

\section{METHODS}

Bacterial strains. The C. jejuni strains used to isolate the putative LPS biosynthesis locus were NCTC 11168 and 11351; 


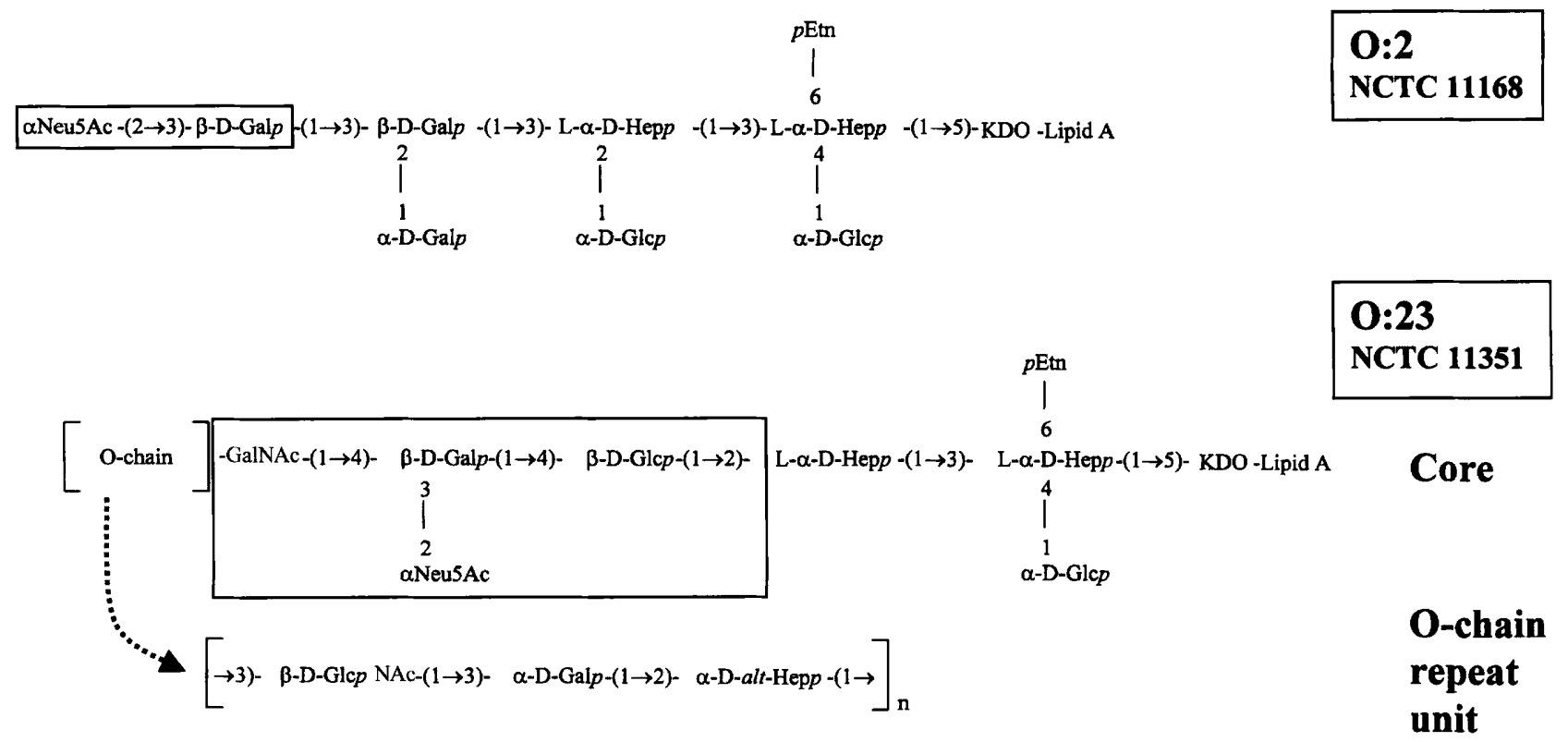

Fig. 1. Chemical structures of the LOS of C. jejuni O:2 (NCTC 11168) (Aspinall et al., 1993a) and LPS of C. jejuni 0:23 (NCTC 11351) Aspinall et al., 1992, 1993b). Boxes denote regions of ganglioside mimicry. KDO, ketodeoxyoctulosonic acid; L- $\alpha$-D-Hepp, L-glycero-D-manno-heptose; Neu5AC, $N$-acetylneuraminic acid; Glc, glucose; Gal, galactose; GICNAC, $N$ acetylglucosamine; GalNAc, $\mathrm{N}$-acetylgalactosamine; $\mathrm{pEtn}$, phosphorylethanolamine.

the former produces LOS and is from serotype group 2, the latter strain is the type strain of C. jejuni, produces LPS and is from serotype group 23. The LPS/LOS from both these serotypes has been characterized chemically (Fig. 1) (Aspinall et al., 1993a, b, 1992). Genetic manipulations were performed using C. jejuni NCTC 11168 and NCTC 11828, the latter is an LPS producer of serotype 6 and was used due to the nontransformability of NCTC 11351. Strains for genetic-distribution studies were obtained from various sources and are detailed in Table 1. All strains were confirmed as C. jejuni using the PCR identification system described by Gonzalez et al. (1997). All Campylobacter strains used in this study were cultured on Campylobacter serum-free agar (Oxoid) or in Mueller-Hinton broth at $37^{\circ} \mathrm{C}$ in microaerophilic conditions $\left(85 \% \mathrm{~N}_{2}, 10 \% \mathrm{CO}_{2}, 5 \% \mathrm{O}_{2}\right)$.

DNA extraction. DNA was extracted using either the method of Pitcher et al. (1989) or an adaptation of the method of Murray \& Thompson (1980). Briefly, for the second method, three lawn plates of Campylobacter were grown overnight, harvested into $9.5 \mathrm{ml}$ of phosphate-buffered saline and lysed with $2 \mathrm{ml} 10 \%(\mathrm{w} / \mathrm{v}$ ) SDS. Proteinase $\mathrm{K}$ was added to a final concentration of $0.2 \mathrm{mg} \mathrm{ml}^{-1}$ and the mixture incubated at $37^{\circ} \mathrm{C}$ for $1 \mathrm{~h}$. Then $1.8 \mathrm{ml} 5 \mathrm{M}$ sodium chloride and $1.5 \mathrm{ml}$ $10 \%(\mathrm{w} / \mathrm{v})$ CTAB $(N$-cetyl-N,N,N-trimethylammonium bromide) in $0.7 \mathrm{M}$ sodium chloride were added and the mixture incubated for $20 \mathrm{~min}$ at $65^{\circ} \mathrm{C}$. An equal volume of $24: 1$ chloroform/isoamyl alcohol was added and the mixture centrifuged for $20 \mathrm{~min}$ at $4{ }^{\circ} \mathrm{C}$. The aqueous layer was removed and the DNA precipitated with 0.7 vols 2-propanol.

Sequence determination. The DNA sequence was determined from a series of nested deletions using the M13 primers (Table 2) in a PCR-based reaction using dye-labelled dideoxy terminators (Perkin-Elmer) and analysed using an ABI 377 sequencer (Perkin-Elmer). Where possible, the new bacterial polysaccharide gene nomenclature system of Reeves et al. (1996) was employed; old names are in parentheses.

PCR primers and conditions. PCR reactions were carried out in a final volume of $10 \mu \mathrm{I}$ and consisted of $1 \mathrm{ng}$ template DNA, 2 pmol each primer (Table 2), $0.2 \mathrm{mM}$ dNTPs, $0.5 \mathrm{U}$ Taq polymerase using a buffer consisting of $10 \mathrm{mM}$ Tris $/ \mathrm{HCl}$, pH 8.3, $50 \mathrm{mM} \mathrm{KCl}, 1.5 \mathrm{mM} \mathrm{MgCl}_{2}$. Amplification consisted of 26 cycles of denaturation at $95^{\circ} \mathrm{C}$ for $30 \mathrm{~s}$, primer annealing at $55^{\circ} \mathrm{C}$ for $1 \mathrm{~min}$ and extension at $72{ }^{\circ} \mathrm{C}$ for $7 \mathrm{~min}$.

Mutation of C. jejuni. C. jejuni chromosomal mutants can be made by transformation with a mutant construct of the gene of interest in the cloning vector pUC19. pUC19 acts as a suicide vector in C. jejuni and can be introduced into the bacterium by electroporation. Subsequent homologous recombination and gene replacement results in the insertion of the mutant gene into the Campylobacter chromosome with the loss of the vector.

Transformation of C. jejuni was performed using a modification of the method of Wassenaar et al. (1993) as follows. Four overnight lawn plates of $C$. jejuni were harvested into $20 \mathrm{ml} \mathrm{WE} \mathrm{buffer} \mathrm{(272} \mathrm{mM}$ sucrose, $15 \%, \mathrm{v} / \mathrm{v}$, glycerol). The cells were washed twice in WE and resuspended in a final volume of $1 \mathrm{ml}$ WE. Approximately $4 \mu \mathrm{g}$ plasmid DNA and $50 \mu$ lelectrocompetent $C$. jejuni cells were placed on ice for 10 min, then electroporated using $2.5 \mathrm{kV}, 200 \Omega$ and $25 \mu \mathrm{F}$. The bacteria were recovered overnight without antibiotic selection, transferred to appropriate antibiotic-containing plates $(50 \mu \mathrm{g}$ kanamycin $\mathrm{ml}^{-1}$ or $20 \mu \mathrm{g}$ chloramphenicol $\mathrm{ml}^{-1}$ ) to select for transformants and incubated for $2-5 \mathrm{~d}$ at $37^{\circ} \mathrm{C}$.

LPS analysis. Late-exponential phase bacterial cells $(1.0 \mathrm{ml}$; $\left.\mathrm{OD}_{600} 0.6\right)$ were pelleted by centrifugation $(3200 \mathrm{~g}, 20 \mathrm{~min}$, $4{ }^{\circ} \mathrm{C}$ ). Pellets were resuspended in $200 \mu \mathrm{l}$ SDS-PAGE loading buffer (Sambrook et al., 1989) and boiled for $10 \mathrm{~min}$. 
Table 1. Characteristics of strains used in genetic distribution studies

ND, Not done, NK, not known, UT, untypeable.

\begin{tabular}{|c|c|c|c|c|}
\hline $\begin{array}{l}\text { C. } \text { jejuni } \\
\text { strain }\end{array}$ & O serotype & Phenotype* & orfE & Source/reference $†$ \\
\hline NCTC 11168 & 2 & LOS & + & R. Owen ${ }^{1}$ \\
\hline $1915 / 91$ & 2 & LOS & + & D. Wareing ${ }^{2}$ \\
\hline $2561 / 90$ & 2 & LOS & + & D. Wareing \\
\hline $2608 / 90$ & 4 & LOS & + & D. Wareing \\
\hline 27F 155 & ND & NK & + & A. $S w a n^{3}$ \\
\hline $18 \mathrm{~F} 5$ & 11 & NK & + & A. Swan \\
\hline $2 \mathrm{~F} 8$ & 5 & NK & + & A. Swan \\
\hline $4 \mathrm{~F} 182$ & ND & NK & + & A. Swan \\
\hline $2 \mathrm{~F} 68$ & 50 & NK & + & A. Swan \\
\hline N82 & UT & NK & + & Everest et al. (1992) \\
\hline K85 & 2 & LOS & + & Everest et al. (1992) \\
\hline G1 $\neq$ & 1 & LOS & + & N. Gregson ${ }^{4}$ \\
\hline G2 $\ddagger$ & UT & NK & + & N. Gregson \\
\hline G3 $\ddagger$ & 1 & LOS & + & N. Gregson \\
\hline G4 $\ddagger$ & UT & NK & + & N. Gregson \\
\hline F3S & UT & NK & + & N. Gregson \\
\hline P19 & 19 & LPS & + & N. Gregson \\
\hline NCTC 11351 & 23 & LPS & - & R. Owen \\
\hline NCTC 11828 & 6 & LPS & - & T. Wassenaar ${ }^{5}$ \\
\hline $2523 / 90$ & 2 & LOS & - & D. Wareing \\
\hline $306 / 90$ & 1 & LOS & - & D. Wareing \\
\hline $2258 / 90$ & 23 & LPS & - & D. Wareing \\
\hline 21F 185 & 15 & NK & - & A. Swan \\
\hline $21 \mathrm{~F} 242$ & ND & NK & - & A. Swan \\
\hline $2 \mathrm{~F} 90$ & UT & NK & - & A. Swan \\
\hline $4 F 225$ & UT & NK & - & A. Swan \\
\hline 8 F 169 & 5 & NK & - & A. Swan \\
\hline B404 & ND & NK & - & Everest et al. (1992) \\
\hline $\mathrm{J} 75$ & 28 & NK & - & Everest et al. (1992) \\
\hline $\mathrm{O} 73$ & 11 & NK & - & Everest et al. (1992) \\
\hline E206 & UT & NK & - & Everest et al. (1992) \\
\hline $81-176$ & $23 / 36$ & LPS & - & Russell et al. (1989) \\
\hline 16971.94GSH & 41 & LOS & - & A. Lastovica ${ }^{6}$, and Prendergast et al. (1998) \\
\hline 28134.94GSH $\ddagger$ & 41 & LOS & - & A. Lastovica, and Prendergast et al. (1998) \\
\hline 260.94RXH‡ & 41 & LOS & - & A. Lastovica, and Prendergast et al. (1998) \\
\hline 176.83 & 41 & LOS & - & A. Lastovica, and Prendergast et al. (1998) \\
\hline
\end{tabular}

* Phenotype is predicted from that reported for each O serotype.

$\dagger^{1}$ National Collection of Type Cultures, Colindale, London, UK; 'Public Health Laboratory, Royal Preston Hospital, Preston, UK; ${ }^{3}$ Public Health Laboratory, Leicester Royal Infirmary, Leicester, UK; ${ }^{4}$ Guy's Medical School, London, UK; ${ }^{5}$ University of Mainz, Germany; ${ }^{6}$ Dept Medical Microbiology, Red Cross Children's Hospital, Cape Town, South Africa.

† indicates a strain from a GBS patient.

Sindicates strain from Miller-Fisher patient.

Proteinase $\mathrm{K}$ was added to a final concentration of $0.5 \mathrm{mg} \mathrm{ml}^{-1}$ and the samples incubated for $2 \mathrm{~h}$ at $65^{\circ} \mathrm{C}$.

Tricine SDS-PAGE was performed according to the method of Sprott et al. (1994) with the following alterations. Final concentrations of 15 or $18 \%(\mathrm{w} / \mathrm{v})$ acrylamide, $0.4 \%(\mathrm{w} / \mathrm{v})$ ammonium persulphate and $0.04 \%(\mathrm{v} / \mathrm{v})$ TEMED $\left(N, N, N^{\prime}\right.$,$N^{\prime}$-tetramethylethylenediamine) were used for the running gel; $0.5 \%(\mathrm{w} / \mathrm{v})$ ammonium persulphate and $0.2 \%(\mathrm{v} / \mathrm{v})$
TEMED were used for the stacking gel. Proteinase K-treated samples were boiled for $5 \mathrm{~min}, 10 \mu$ loaded per well of a $16 \mathrm{~cm}$ gel and electrophoresed at $15 \mathrm{~mA}$ per gel for $16 \mathrm{~h}$. Gels were either silver stained (Tsai \& Frasch, 1982) or gel to nitrocellulose transfers were made. Primary antibody was used at a dilution of $1 / 2500$ for $0: 6$ antiserum or $1 / 5000$ for $0: 2$ antiserum and detected using the Bio-Rad Immun-Star Western blotting kit. 
Table 2. PCR primers used in this study

\begin{tabular}{|c|c|c|c|}
\hline Primer & Sequence $\left(5^{\prime}-3^{\prime}\right)$ & Target & Reference \\
\hline JEJ1 & CCTGCTACGGTGAAAGTTTTGC & $c e u E$ & Gonzalez et al. (1997) \\
\hline JEJ2 & GATCTTTTTGTTTTGTGCTGC & $c e u E$ & Gonzalez et al. (1997) \\
\hline COL1 & ATGAAAAAATATTTAGTTTTTGCA & $c e u E$ & Gonzalez et al. (1997) \\
\hline COL2 & ATTTTATTATTTGTAGCAGCG & $c e u E$ & Gonzalez et al. (1997) \\
\hline M13F & GTAAAACGACGGCCAGT & pUC19 & Yanisch-Perron et al. (1985) \\
\hline M13R & AACAGCTATGACCATG & pUC19 & Yanisch-Perron et al. (1985) \\
\hline $\mathrm{XR} 2$ & CGCGGATCCACTATATAGTGAAC & orfE & This study \\
\hline XR1 & CCACCCCAAAGGCGAAGG & orfE & This study \\
\hline CAPDF2 & GGAAGATCTAGTGGAGATATTCCG & orfG (capD homologue) & This study \\
\hline CAPDR2 & GGAAGATCTCAAAGAAAAAGCCAG & orfG (capD homologue) & This study \\
\hline XR3 & GGAAGATCTAAATGCAATTTACATCC & orfE-orfD & This study \\
\hline CATF1 & TAGTGGTCGAAATACTCTTTTCGTG & CAT & This study \\
\hline STTF1 & TATCTACGCTTACTTATTGGCT & orfA & This study \\
\hline WBBOF1 & GCGCCTAGGGTGCCGCAAGATGAATACACGC & orf $B$ ( $w b b O$ homologue) & This study \\
\hline WBAPF1 & CGGTGATTTTAATCACTGC & orfC (wbaP homologue) & This study \\
\hline NEUDF1 & GCGCCTAGGGGGCTTGTTTGTGAAGATGTGGC & orfD (neuD homologue) & This study \\
\hline NADHF1 & CCACCCCAAAGGCGAAGG & orfE & This study \\
\hline WBEEF1 & CAAAAGCAATTATATAGCAC & orfF (wbeE homologue) & This study \\
\hline CAPDR1 & CGGAATATCTCCACTAAATCTC & orfG (capD homologue) & This study \\
\hline
\end{tabular}

\section{RESULTS}

\section{Cloning the putative LPS-biosynthesis locus}

C. jejuni chromosomal libraries from C. jejuni NCTC 11168 and 11351 strains were constructed by ligating Bcll-restricted chromosomal DNA and pUC19 restricted with $B a m H I$. Clones of interest were identified from both strains using a ${ }^{32} \mathrm{P}$-labelled $800 \mathrm{bp}$ DNA fragment encoding part of a $w b a P(r f b P)$ homologue, derived from C. jejuni NCTC 11828 (a gift from B. Fry and B. van der Zeijst, Utrecht, The Netherlands). A single positive plasmid clone, confirmed to be representative of the chromosomal locus by Southern hybridization (data not shown), was selected from each strain. The plasmid from NCTC 11168 was designated pAWL61, and that from NCTC 11351, pAWL31.

\section{Sequence analysis}

The insert of pAWL61 was $7082 \mathrm{bp}$ and encoded five complete and two partial ORFs, whereas the pAWL31 insert was $6478 \mathrm{bp}$ and lacked one of the ORFs present in pAWL61. Restriction enzyme profiles of both plasmid clones were determined and the ORFs identified (Fig. 2). The predicted amino acid sequences from the seven ORFs were used to identify homologous proteins using the EMBL database and the BLAST program (Altschul et al., 1990). Six of the predicted protein sequences showed homology to proteins known to be involved in polysaccharide biosynthesis in other microbes (Table 3). However, the predicted protein sequence from the additional gene in pAWL61 (orfE) demonstrated only very low homology with any proteins in the database.

\section{Distribution and organization of the putative LPS locus in C. jejuni}

Variation in the sugar composition of $\mathrm{O}$-chains within a species is often reflected by gene insertions, deletions or mutations within the biosynthesis locus (Schnaitman \& Klena, 1993). Variation at the putative LPS biosynthesis locus of $C$. jejuni was investigated using specific primers (Table 2) in a PCR-based approach. Amplification was performed from a reverse anchor primer, CAPDR1, specific for orfG, to each of a series of forward primers for the other six genes. This approach was applied to both C. jejuni NCTC 11168 and NCTC 11351 chromosomal DNA to confirm the integrity of the PCR approach (Fig. 3, Table 1).

A further 34 strains of $C$. jejuni were analysed using the same approach as used for NCTC 11168 and NCTC 11351, but no additional variation was seen within the locus. Of these 34 strains, 16 produced an identical PCR profile to C. jejuni NCTC 11168 and 18 strains produced an identical profile to C. jejuni NCTC 11351, lacking orfE (Table 1). The presence or absence of orfE was confirmed by Southern hybridization (data not shown). Serotyping of the strains (Table 1 ) revealed that the presence or absence of orfE did not correlate with serotype or LPS/LOS phenotype. Seven strains from GBS patients were included in the screening, four contained orfE and three did not (Table 1).

\section{Mutational analysis}

Mutation of C. jejuni strains was carried out by electroporation using pUC19-based plasmids as described above in Methods. C. jejuni NCTC 11351 proved to be untransformable and therefore NCTC 11828 was 


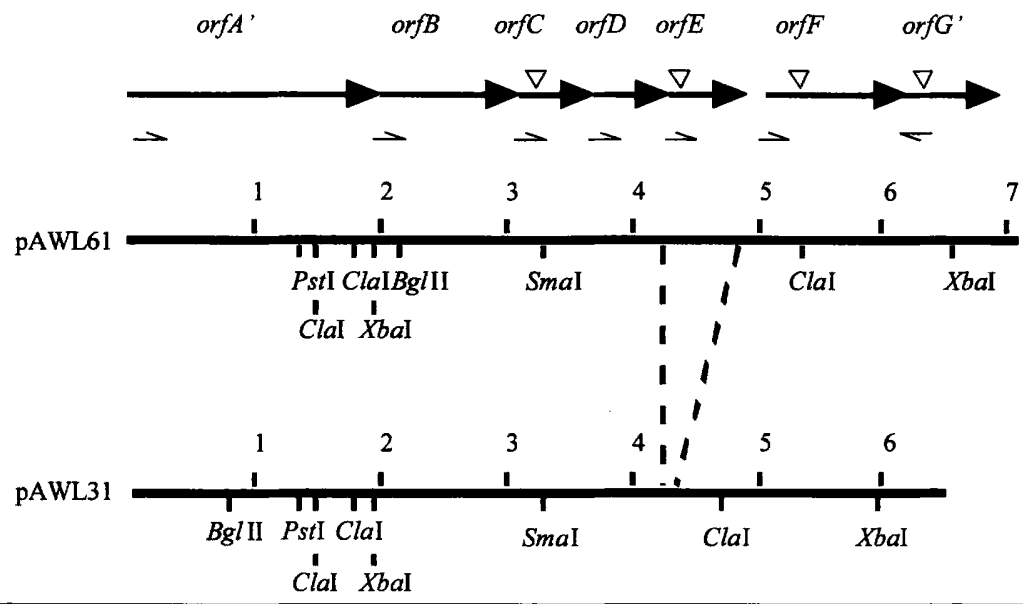

Fig. 2. Restriction map and ORFs (arrows) of clones PAWL61 and pAWL31. The insert of pAWL61 is derived from $C$. jejuni NCTC 11168 and is 7082 bp in length, pAWL31 is derived from NCTC 11351 and is 6478 bp in length. orfA and orfG are incomplete. The dashed line indicates the region where the two clones differ; white triangles represent positions of mutations described in the text; half arrows indicate positions and direction of primers used in the genetic distribution studies.

Table 3. Analysis of predicted protein sequences from the ORFs of pAWL61

\begin{tabular}{|c|c|c|c|c|}
\hline ORF & $\begin{array}{l}\text { Size } \\
\text { (bp) }\end{array}$ & Protein with highest homology* & Proposed function & $P+/$ identity \\
\hline $\begin{array}{l}\operatorname{orf} A \\
\text { (incomplete) }\end{array}$ & 1996 & $\begin{array}{l}\text { Saccharomyces cerevisiae STT3 (S64024) (Yoshida et al., } \\
\text { 1995) }\end{array}$ & $\begin{array}{l}\text { Oligosaccharyl transferase } \\
\text { subunit }\end{array}$ & $2 \times 10^{-7} / 19 \%$ \\
\hline orfB & 1131 & $\begin{array}{l}\text { Campylobacter hyoilei WbbO (RfbF) (X91081) (Korolik et } \\
\text { al., 1997) }\end{array}$ & Galactosyl transferase & $2.8 \times 10^{-218} / 80 \%$ \\
\hline orfC & 603 & $\begin{array}{l}\text { Campylobacter hyoilei WbaP (RfbP) (X91081) (Korolik et } \\
\text { al., 1997) }\end{array}$ & $\begin{array}{l}\text { UDP-galactose phosphate } \\
\text { transferase }\end{array}$ & $4.6 \times 10^{-132} / 95 \%$ \\
\hline orfD & 588 & E. coli NeuD (I55145) (Annunziato et al., 1995) & Acetyl transferase & $1 \times 10^{-25} / 29 \%$ \\
\hline orfE & 654 & $\begin{array}{l}\text { Anopheles quadrimaculatus NADH dehydrogenase (L04272) } \\
\text { (Mitchell et al., 1993) }\end{array}$ & NADH dehydrogenase & $0 \cdot 06 / 19 \%$ \\
\hline orf $F$ & 1161 & Vibrio cholerae WbeE (RfbE) (S28471) (Stroeher et al., 1995) & Dideoxyhexose synthesis & $3 \times 10^{-59} / 31 \%$ \\
\hline $\begin{array}{l}\text { orfG } \\
\text { (incomplete) }\end{array}$ & 909 & Staphylococcus aureus CapD (U10927) (Lin et al., 1994) & Capsule synthesis & $3 \times 10^{-17} / 27 \%$ \\
\hline
\end{tabular}

* The predicted protein sequences were analysed using the GenBank/EMBL database and the BLASTP analysis program (Altschul et al., 1990). Old names of proteins are in parentheses. Alphanumeric figures are the protein accession numbers in the GenBank/EMBL database. † The probability score $(P)$ gives an indication of the confidence with which the identification was made; low numbers indicate high probability.

(a)

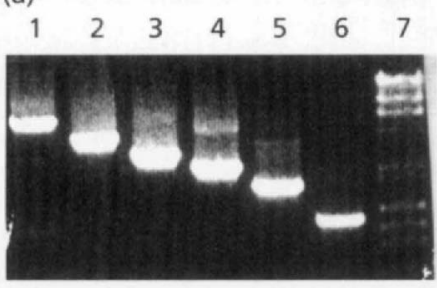

(b)

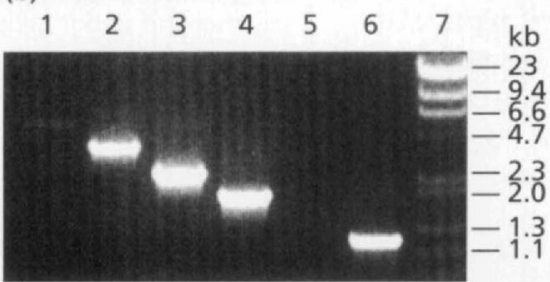

Fig. 3. PCR profiles of C. jejuni NCTC 11168 and NCTC 11351. Six specific PCR products are seen corresponding to the seven known genes with $C$. jejuni NCTC 11168 (a), whereas five bands only are seen with $C$. jejuni NCTC 11351 (b). The lack of product in lane 5 correlates with the absence of orfE. The amplicons in lanes 1-4 with NCTC 11351 are approximately $600 \mathrm{bp}$ smaller than those with NCTC 11168, also correlating with the absence of orfE. In both parts: lane1, orfA-G; lane 2, orfB-G; lane 3, orfC-G; lane 4, orfD-G; lane 5, orfE-G; lane 6, orfF-G; lane $7, \lambda$ HindIII and $\phi \times 174$ HaellI molecularmass markers. used for the mutational analysis as it is a LPS producer and has an identical genetic complement at this locus to NCTC 11351. A kanamycin-resistance cassette derived from Campylobacter coli (Trieucuot et al., 1985) was used to mutate orf $E, F$ and $G$ in NCTC 11168 and orf $F$ and $G$ in NCTC 11828. orfE and orfG were mutated 
(a)

(b)

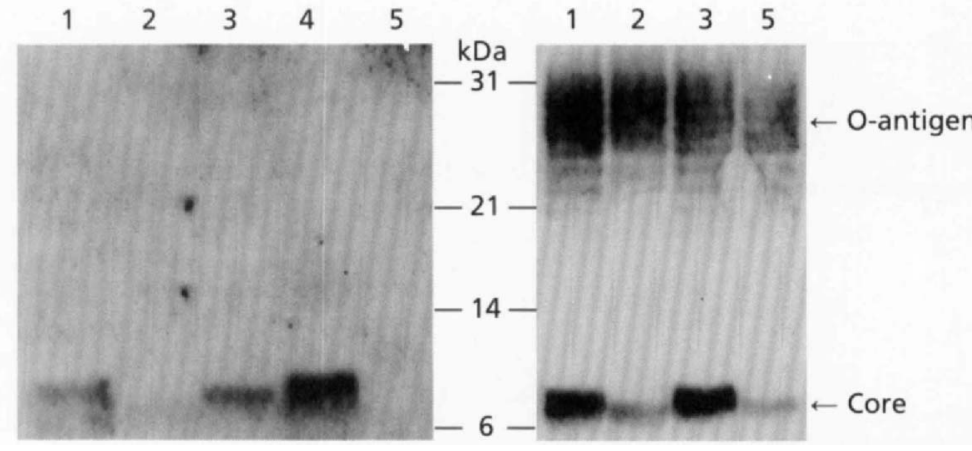

Fig. 4. C. jejuni LPS/LOS profiles. LPS/LOS samples were electrophoresed on an $18 \%$ SDS-PAGE gel using the Tricine buffering system of Sprott et al. (1994) and subsequently detected by Western blotting using (a) 0:2 antiserum against NCTC 11168 and its mutants and (b) $0: 6$ antiserum against NCTC 11828 and its mutants. In both panels lane 1, C. jejuni wild-type; 2, orfF mutant; 3, orfG mutant; 4, orfE mutant; 5 , large deletion mutant.

using inverse-PCR mutagenesis (Wren et al., 1994) and primers XR1/XR2 and CAPDF2/CAPDR2, respectively (Table 2), whereas orfF was mutated by inserting the kanamycin cassette into the ClaI site within the gene. Attempts were also made to mutate the wbaP homologue, orfC, utilizing the SmaI site, but no transformants were obtained with either C. jejuni strain. Despite this, it proved possible to create a large deletion of the central two ClaI bands from the locus, removing the $3^{\prime}$ end of $\operatorname{orf} A$, all of $\operatorname{orf} B, C, D$ and $E$, and the $5^{\prime}$ end of orfF. One possible explanation may be the toxic build-up of a pathway intermediate when orfC alone is mutated, such as occurs in Escherichia coli galE mutants when a build-up of UDP-galactose leads to cell lysis in the presence of galactose (Nikaido, 1961).

LOS/LPS samples from the wild-type and mutant strains of C. jejuni were analysed by Western blotting; the $\mathrm{O}$ chain ladder of $C$. jejuni is not detectable by silver staining, only by Western blotting. Mutation of orfG had no detectable effect on the LOS/LPS profiles of either strain (Fig. 4, lanes 3). Mutation of orfE in NCTC 11168 did not alter the LOS profile of this strain (Fig. 4a, lane 4); the equivalent experiment in NCTC 11828 is not possible as orfE is not present. Mutating orfF and deleting the central ClaI fragments altered the reactivity of the core molecule to antiserum (Fig. 4, lanes 2 and 5). No effect on O-chain production was detected by Western blotting in any of the mutants constructed. The mutants were also analysed by silver staining, but no consistent alteration was detected with any of the mutants (data not shown). Mobility changes were occasionally seen in core molecules (shown in Fig. 4b, lane 2); however, these changes were not consistently observed. The orfF mutant and the large deletion mutant also demonstrated an altered morphology when compared with the wild-type; both these mutants were shorter and wider than their parent (Fig. 5).

\section{Analysis of orfE}

The genetic distribution analysis of the locus in C. jejuni confirmed that the only significant variation within the locus was the presence/absence of orfE, but this variation did not correlate with serotype or the presence of O-chain. Mutation of orfE in the LOS-producing NCTC 11168 had no detectable effect on LOS pheno-
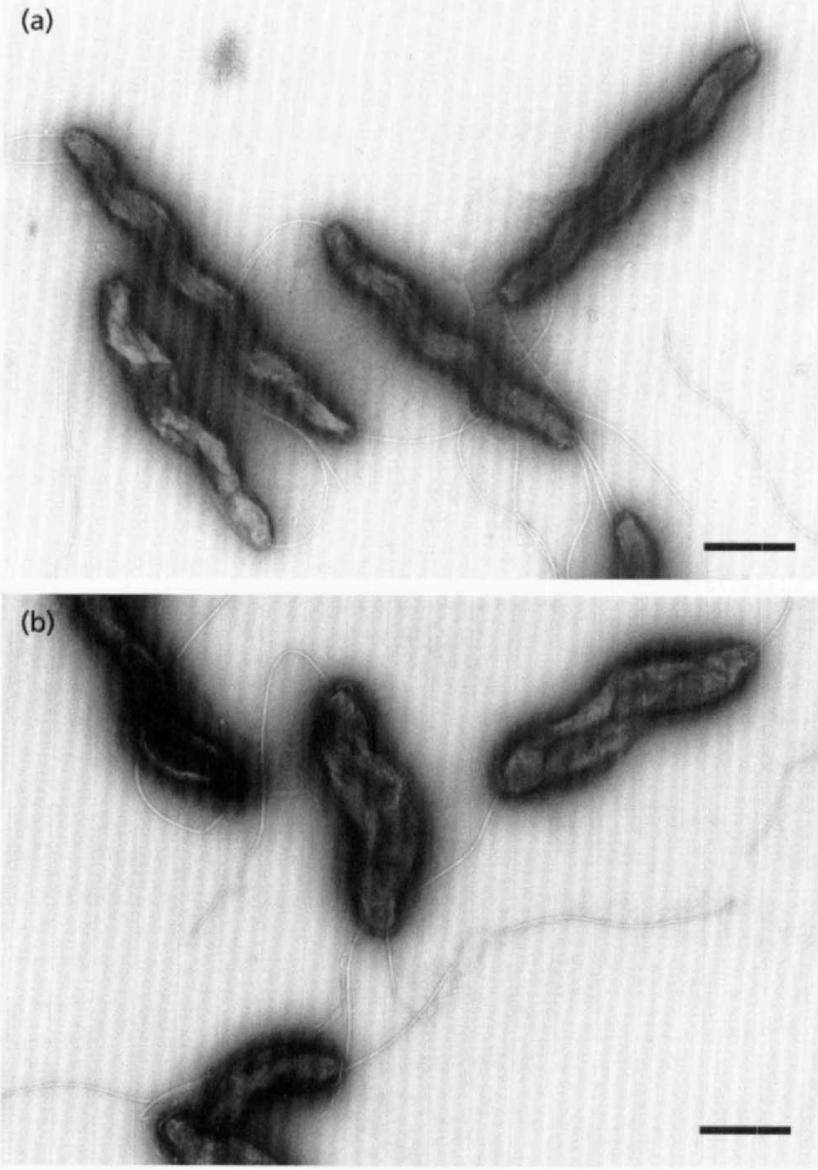

Fig. 5. Electron micrograph of negatively stained NCTC 11168 (a) and orff mutant (b) illustrating that the mutation results in shorter and wider cells (Bars, $1 \mu \mathrm{m}$ ).

type, but this was dependent upon the alteration being detected by the $O: 2$ antiserum and did not indicate what its effect might be on LPS. A strategy was therefore designed to insert orfE into an LPS producer to analyse the effect of adding orfE to this strain. pCOD2 (Fig. 6) was constructed to facilitate the insertion of an intact orfE derived from NCTC 11168 into NCTC 11828 along with an antibiotic-resistance marker, chloramphenicol acetyl transferase (CAT; Wang \& Taylor, 1990; Yao et al., 1993). pCOD2 was used to transform 

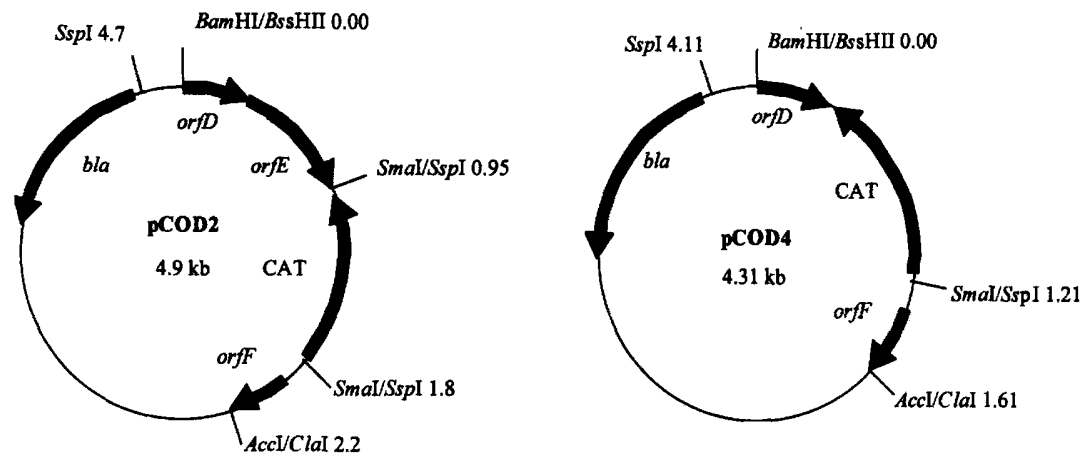

\begin{abstract}
Fig. 6. Schematic diagram of $\mathrm{pCOD2}$ and pCOD4. For pCOD2, the CAT cassette was restricted with Smal and inserted into the Sspl site of a pAWL61 subclone in a threeway ligation.
\end{abstract}

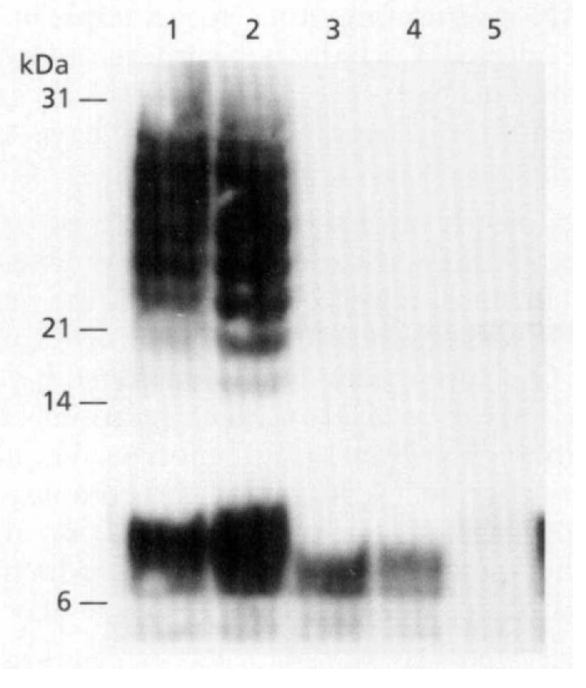

Fig. 7. LPS/LOS profiles of C. jejuni NCTC 11828 with the orfE mutations. LPS/LOS samples were electrophoresed on a $15 \%$ SDS-PAGE gel using the Tricine buffering system of Sprott et al. (1994) and subsequently detected by Western blotting using 0:6 antiserum. O-chains are no longer detectable in the LPS sample from C. jejuni NCTC 11828 with the insertion of orfE (lane 3), disruption of orfE within this mutant does not restore detectability of the O-chain (lane 4). In contrast, the presence of an antibiotic-resistance gene in the same position does not affect 0 -chain production (lane 2 ). The core reactivity of the LPS samples remains in all cases. Lane 1, C. jejuni NCTC 11828; lane 2, C. jejuni NCTC 11828::CAT; lane 3, C. jejuni NCTC 11828::(orfE +CAT); lane 4, C. jejuni NCTC 11828:: (orfE::KAN) + CAT; lane 5, C. jejuni NCTC 11168.

C. jejuni NCTC 11828 and transformants were selected using chloramphenicol. The LPS from NCTC 11828 (orfE absent), NCTC 11168 (orfE present) and the mutant NCTC 11828 containing orfE and CAT [NCTC 11828 : (orfE + CAT)] were analysed by Western blotting using $\mathrm{O}: 6$ antiserum (Fig. 7, lanes 1,5 and 3 , respectively). The LPS of the mutant strain consistently showed no alteration in serospecificity, but the O-chain was no longer detectable (Fig. 7, lane 3).

orfE was subsequently disrupted in the NCTC 11828 :: (orfE + CAT) mutant using a kanamycin-resistancecassette (KAN) insertion in the same manner used to construct the NCTC 11168 orfE mutant (see above). NCTC 11828::(orfE +CAT) was transformed with
orfE containing the KAN cassette and transformants selected using kanamycin. Production of the O-chain was not detected in NCTC $11828::$ (orfE::KAN) + CAT (Fig. 7, lane 4). To determine the effect of the CAT cassette alone on LPS phenotype at the position of insertion of orfE into NCTC 11828, a mutant was created using pCOD4 (Fig. 6). pCOD4 was constructed by inverse-PCR mutagenesis using a primer that anneals to sequence immediately downstream of orfD (XR3; Table 2) and a primer that anneals to the start of the CAT cassette (CATF1; Table 2) with pCOD2 as the template. The NCTC 11828::(CAT) mutant was found to have a detectable O-chain (Fig. 7, lane 2).

\section{DISCUSSION}

A putative LPS-biosynthesis locus was isolated from two strains of C. jejuni, one of which is reported to produce LPS and the other LOS. Predicted gene products from the six common ORFs identified showed similarity to proteins known to be involved with polysaccharide synthesis. Mutations in this locus appeared to affect the antigenicity of the core polysaccharide. The only difference between the gene organization of the two loci was the presence of a seventh gene, orfE, in the LOSproducing strain. The function of the orfE gene product is not known, although it has a low level of homology to several dehydrogenase genes.

The locus we have isolated does not encode all the genes required for LPS or LOS synthesis and therefore, not surprisingly, the presence of plasmid pAWL61 did not confer the production of Campylobacter-specific core or O-chain upon the host strain E. coli DH5 $\alpha$. We have evidence indicating the presence of further LPS-biosynthesis genes upstream, but it has not yet been possible to clone the entire region to examine its effect on $E$. coli due to cosmid instability. Our preliminary data $(\mathrm{N}$. J. Oldfield \& J. M. Ketley, unpublished results) suggest that genetic variation in LPS-biosynthesis-gene content lies within this uncharacterized region upstream of the locus reported here.

In Salmonella, WbaP transfers galactose 1-phosphate to undecaprenol phosphate as an initiation step in the assembly of some O-chain subunits. The presence of a WbaP homologue (OrfC) in both strains would suggest 
that a biosynthesis mechanism involving a lipid carrier, similar to that for O-chain synthesis, exists within $C$. jejuni. The lack of an O-chain in NCTC 11168 suggests that the genes either are not expressed or are involved in the biosynthesis of structures other than O-chain, such as core oligosaccharide. The first hypothesis is unlikely due to the inability to create a single wbaP mutant; we also have preliminary data (not shown) indicating that the locus is expressed in NCTC 11168. The lack of effect on the O-chain noted when the majority of the genes in the locus were deleted also suggests that the genes are not involved in O-chain synthesis. This observation and the alteration in reactivity to antiserum noted with the core of the orfF mutant support the hypothesis that the genes are involved in core synthesis.

The deduced amino acid sequence of OrfF showed homology to WbeE (RfbE; putative perosamine synthase) from Vibrio cholerae (Stroeher et al., 1995) and DdhC (RfbH; CDP-4-keto-6-deoxy-D-glucose 3-dehydrase) from Salmonella typhimurium (Schnaitman \& Klena, 1993), both of which are involved in dideoxyhexose synthesis suggesting that OrfF may also be involved in such a pathway. The relatively high conservation of the locus throughout several serotypes suggests that the region is involved in the synthesis of a common part of LPS/LOS molecules. The only known constituent of the core in a $\mathrm{O}: 2$ serotype that contains a dideoxy component is sialic acid. It is also interesting to note the high homology of OrfD to $\mathrm{NeuD}$, a protein thought to be involved in sialic acid capsule synthesis in E. coli (Annunziato et al., 1995). The reduced reactivity of antiserum with the core of the LPS and LOS molecules in an orfF mutant indicates that OrfF may be involved in core biosynthesis. It is notable that the effect of an orfF mutation on core oligosaccharide does not disturb Ochain biosynthesis in NCTC 11828; there are a number of possible reasons for this result. First, the action of OrfF may produce a minor variation in core structure that results in a change in antigenicity but not $\mathrm{O}$-chain linkage. Second, C. jejuni may make more than one core structure (although this is not supported by structural studies) which are not all linked to O-chain. Thus, OrfF may be involved in the biosynthesis of an unlinked core region. Third, the O-chain ladder may reflect the production of a capsule-like extracellular polysaccharide (see below) and therefore changes in LOS core polysaccharide may not affect such an 'O-chain' molecule.

There are several explanations for the inability to detect any phenotypic alteration when mutating orfE or orfG. The polyclonal antiserum used in the Western blot may not detect minor changes in the structure of the LPS. Another possibility is the presence of compensating genes in a second LPS biosynthesis locus. We have used Southern hybridization and PCR to test this hypothesis and have found no evidence of a second locus (data not shown). Cryptic LPS-biosynthesis genes have been documented in Neisseria (Robertson et al., 1994; Preston et al., 1996) and Haemophilus influenzae (Hood et al., 1996), both of which produce LOS, but not LPS.
Insertional mutagenesis of several genes from both these species failed to alter their LOS profiles.

Given that the locus may be involved in core oligosaccharide biosynthesis, interpretation of our data at the present time is complicated by the fact that the O-chain is no longer visible after the insertion of orf $E$ into the LPS producer. Subsequent disruption of this gene by insertion of a KAN cassette does not restore the visibility of the O-chain; however, the presence of the CAT cassette alone did not affect O-chain biosynthesis. Therefore, it is the presence of orfE and not the position of insertion that is of importance. The product of the KAN cassette or the orientation of the KAN or CAT cassette are not responsible for the loss of $\mathrm{O}$-chain, as other KAN-insertion mutants (for example in orfG) do not have altered O-chain biosynthesis and orfE-containing mutants with the KAN and CAT cassettes in both orientations (data not shown) have the same mutant phenotype.

We are currently investigating the role of orfE in $\mathrm{O}$ chain production, but our data show that, when inserted into the chromosome of NCTC 11828, the presence of orf $E$ can affect LPS/LOS phenotype. If orf $E$ can have an effect on O-chain production as suggested by our data, we would have expected to see a correlation between the presence of orfE and the LOS phenotype. The absence of such a correlation might reflect the complexity of $\mathrm{O}$ chain biosynthesis, where the presence or absence of many other genes will also affect the production of $\mathrm{O}$ chain and strains of a particular serotype may not have identical O-chain structure.

Extracellular polysaccharides that are not attached to lipid A core structures have been described in C. jejuni (Áspinall et al., 1995; Prendergast et al., 1998). It is possible, therefore, that C. jejuni also contains genes that encode enzymes involved in the production of (an)other extracellular polysaccharide(s) and produce a lipid-linked polysaccharide, rather than LPS. One group postulated that the Penner serotyping screen is actually a reflection of capsule content (Chart et al., 1996); however, the antigen treatment described by Chart et al. (1996) does not rule out the involvement of LPS. Interestingly, part of an $\mathrm{ABC}$-transporter system with closest similarity to genes involved in capsular extracellular-polysaccharide biosynthesis have been identified in C. jejuni (A. Karlyshev, personal communication); the mutation of these genes also has an effect on O-chain production in C. jejuni. It is possible that in some $C$. jejuni strains (for example, those without orfE), the extracellular polysaccharide could also be added to a lipid A core. Such a structure would be analogous to the lipid A-core-linked enterobacterial common antigen $\left(\mathrm{ECA}_{\mathrm{LPS}}\right)$ and lipid A-core-linked $\mathrm{K}$ antigen $\left(\mathrm{K}_{\mathrm{LPS}}\right)$ (Whitfield et al., 1997). This may imply that all campylobacters are LOS producers with some strains also containing a polysaccharide structure that is independent of a subset of core oligosaccharide. The genetic analysis presented here does not indicate the nature of the linkage of the $\mathrm{O}$-chain structures observed in some strains of C. jejuni. 
In conclusion, we have isolated a locus encoding ORFs with homology to bacterial polysaccharide-biosynthesis genes and shown that mutating one of the genes in this locus affects the reactivity of antiserum to the core of LPS, although the mutation of two other genes had no effect. None of these mutants demonstrated an altered O-chain. The locus is distributed throughout C. jejuni isolates regardless of serotype; the only variation is the presence of orfE which, at present, is of unknown function. Insertion of orf $E$ into an LPS-producing orfEnegative strain results in the loss of $\mathrm{O}$-chain as seen on Western blots.

\section{NOTE ADDED IN PROOF}

A description of the LPS-biosynthesis locus of Campylobacter jejuni NCTC 11828 (81116) was recently published by Fry et al. (1998).

\section{ACKNOWLEDGEMENTS}

This work was funded by the UK Department of Health, and the Biotechnology and Biological Sciences Research Council. We would like to thank the Royal Society for a University Research Fellowship to J.M.K. We gratefully acknowledge B. Fry and B. van der Zeijst, Department of Bacteriology, Faculty of Veterinary Medicine, Utrecht University, The Netherlands for the NCTC 11828 DNA fragment; E. Bolton, Preston Public Health Laboratory, UK and J. Frost, Central Public Health Laboratory, London, UK for antiserum; R. Thwaites, Central Public Health Laboratory, Colindale, London, UK for serotyping; all those who supplied isolates for the genetic distribution studies (listed in Table 1); R. Owen, Central Public Health Laboratory, London, UK for C. jejuni NCTC 11168 and NCTC 11351; T. Wassenaar, University of Mainz, Germany for C. jejuni NCTC 11828 . We would also like to thank J. ten-Brinke, Department of Bacteriology, Faculty of Veterinary Medicine, Utrecht University, The Netherlands for technical assistance; A. Moran, Department of Microbiology, University College Galway, Ireland, for help with the O:41 strains and D. Maskell, Dept of Clinical Veterinary Medicine, University of Cambridge, Cambridge, UK for helpful discussions.

\section{REFERENCES}

Altschul, S. F., Gish, W., Miller, W., Myers, E. W. \& Lipman, D. J. (1990). Basic local alignment tool. J Mol Biol 215, 403-410.

Annunziato, P. W., Wright, L. F., Vann, W. F. \& Silver, R. P. (1995). Nucleotide sequence and genetic analysis of the neuD and neuB genes in region 2 of the polysialic acid gene cluster of Escherichia coli K1. J Bacteriol 177, 312-319.

Aspinall, G. O., McDonald, A. G. \& Pang, H. (1992). Structures of the $O$ chains from lipopolysaccharides of Campylobacter jejuni serotypes $\mathrm{O}: 23$ and $\mathrm{O}: 36$. Carbobydr Res 231, 13-30.

Aspinall, G. O., McDonald, A. G., Raju, T. S., Pang, H., Kurjanczyk, L. A., Penner, J. L. \& Moran, A. P. (1993a). Chemical structures of the core region of Campylobacter jejuni serotype O:2 lipopolysaccharide. Eur J Biochem 213, 1029-1037.

Aspinall, G. O., McDonald, A. G., Raju, T. S., Pang, H., Moran, A. P. \& Penner, J. L. (1993b). Chemical structures of the core regions of Campylobacter jejuni serotypes $\mathrm{O}: 1, \mathrm{O}: 23$ and $\mathrm{O}: 36$ lipopolysaccharides. Eur J Biochem 213, 1017-1027.
Aspinall, G. O., McDonald, A. G., Pang, H., Kurjanczyk, L. A. \& Penner, J. L. (1994). Lipopolysaccharides of Campylobacter jejuni serotype $\mathrm{O}: 19$ structures of core oligosaccharide regions from the serostrain and two bacterial isolates from patients with the Guillain-Barré syndrome. Biochemistry 33, 241-249.

Aspinall, G. O., Lynch, C. M., Pang, H., Shaver, R. T. \& Moran, A. P. (1995). Chemical structures of the core regions of Campylobacter jejuni O:3 lipopolysaccharide and an associated polysaccharide. Eur J Biochem 231, 570-578.

Chart, H., Frost, J. A., Oza, A., Thwaites, R. \& Gillander, S. (1996). Heat-stable serotyping antigens expressed by strains of Campylobacter jejuni are probably capsular and not long-chain lipopolysaccharides. J Appl Bacteriol 81, 635-640.

Everest, P. H., Goossens, H., Butzler, J. P., Lloyd, G., Knutton, S., Ketley, J. M. \& Williams, P. H. (1992). Differentiated CaCo-2 cells as a model for enteric invasion by Campylobacter jejuni and $C$. coli. J Med Microbiol 37, 319-325.

Fry, B. N., Korolik, V., ten Brinke, J. A., Pennings, M. T. T., Zalm, R., Teunis, B. J. J., Coloe, P. J. \& van der Zeijst, B. A. M. (1998). The lipopolysaccharide biosynthesis locus of Campylobacter jejuni 81116. Microbiology 144, 2049-2061.

Gonzalez, I., Grant, K. A., Richardson, P. T., Park, S. F. \& Collins, M. D. (1997). Specific identification of the enteropathogenic Campylobacter jejuni and Campylobacter coli by using a PCR test based on the ceuE gene encoding a putative virulence determinant. J Clin Microbiol 35, 759-763.

Hood, D. W., Deadman, M. E., Allen, T. \& 7 other authors (1996). Use of the complete genome sequence information of Haemophilus influenzae strain $\mathrm{Rd}$ to investigate lipopolysaccharide biosynthesis. Mol Microbiol 17, 1167-1175.

Ketley, J. M. (1997). Pathogenesis of enteric infection by Campylobacter. Microbiology 143, 5-21.

Korolik, V., Fry, B. N., Alderton, M. R., van der Zeijst, B. A. M. \& Coloe, P. J. (1997). Expression of Campylobacter byoilei lipooligosaccharide (LOS) antigens in Escherichia coli. Microbiology 143, 3481-3489.

Lin, W. S., Cunneen, T. \& Lee, C. H. (1994). Sequence analysis and molecular characterization of genes required for the biosynthesis of type 1 capsular polysaccharide in Staphylococcus aureus. $J$ Bacteriol 176, 7005-7016.

McSweegan, E. \& Walker, R. I. (1986). Identification and characterization of two Campylobacter jejuni adhesins for cellular and mucous substrates. Infect Immun 53, 141-148.

Mishu, B. \& Blaser, M. J. (1993). Role of infection due to Campylobacter jejuni in the initiation of Guillain-Barré syndrome. Clin Infect Dis 17, 104-108.

Mitchell, S. E., Cockburn, A. F. \& Seawright, J. A. (1993). The mitochondrial genome of Anopheles quadrimaculatus species A: complete nucleotide sequence and gene organization. Genome 36, 1058-1073.

Moran, A. P. (1995). Biological and serological characterization of Campylobacter jejuni lipopolysaccharides with deviating lipid A and core structures. FEMS Immunol Med Microbiol 11, 121-130.

Moran, A. P. \& O'Malley, D. T. (1995). Potential role of lipopolysaccharides of Campylobacter jejuni in the development of Guillain-Barré syndrome. J Endotoxin Res 2, 233-235.

Moran, A. P., Rietschel, E. T., Kosunen, T. U. \& Zahringer, U. (1991a). Chemical characterization of Campylobacter jejuni lipopolysaccharides containing $N$-acetylneuraminic acid and 2,3diamino-2,3-dideoxy-D-glucose. J Bacteriol 173, 618-626.

Moran, A. P., Zahringer, U., Seydel, U., Scholz, D., Stutz, P. \& Rietschel, E. T. (1991b). Structural analysis of the lipid A 
component of Campylobacter jejuni CCUG 10936 (serotype 2) lipopolysaccharide. Eur J Biochem 198, 459-469.

Moran, A. P., Prendergast, M. M. \& Appelmelk, B. J. (1996). Molecular mimicry of host structures by bacterial lipopolysaccharides and its contribution to disease. FEMS Immunol Med Microbiol 16, 105-15.

Murray, M. G. \& Thompson, W. F. (1980). Rapid isolation of highmolecular-weight plant DNA. Nucleic Acids Res 8, 4321-4325.

Nikaido, H. (1961). Galactose-sensitive mutants of Salmonella. II. Bacteriolysis induced by galactose. Biochim Biophys Acta 48, $460-469$.

Penner, J. L., Hennessy, J. N. \& Congi, R. V. (1983). Serotyping of Campylobacter jejuni and Campylobacter coli on the basis of thermostable antigens. Eur J Clin Microbiol 2, 378-383.

Pitcher, D. G., Saunders, N. A. \& Owen, R. J. (1989). Rapid extraction of bacterial DNA with guanidinium isothiocyanate. Lett Appl Microbiol 8, 151-156.

Prendergast, M. M., Lastovica, A. J. \& Moran, A. P. (1998). Lipopolysaccharides from Campylobacter jejuni O:41 strains associated with Guillain-Barré Syndrome exhibit mimicry of $\mathrm{GM}_{1}$ ganglioside. Infect Immun 66, 3649-3655.

Preston, M. A. \& Penner, J. L. (1987). Structural and antigenic properties of lipopolysaccharides from serotype reference strains of Campylobacter jejuni. Infect Immun 55, 1806-1812.

Preston, A., Mandrell, R. E., Gibson, B. W. \& Apicella, M. A. (1996). The lipooligosaccharides of pathogenic Gram-negative bacteria. Crit Rev Microbiol 22, 139-180.

Reeves, P. R., Hobbs, M., Valvano, M. A. \& 8 other authors (1996). Bacterial polysaccharide biosynthesis and gene nomenclature. Trends Microbiol 4, 495-503.

Rietschel, E., Kirikae, T., Schade, F. U. \& 9 other authors (1994). Bacterial endotoxin: molecular relationships of structure to activity and function. FASEB $] 8,217-225$.

Robertson, B. D., Frosch, M. \& van Putten, J. P. M. (1994). The identification of cryptic rhamnose biosynthesis genes and their relationship to lipopolysaccharide biosynthesis. J Bacteriol 176, $6915-6920$.

Russell, R. G., Blaser, M. J., Sarmiento, J. I. \& Fox, J. (1989). Experimental Campylobacter jejuni infection in Macaca nemestrina. Infect Immun 57, 1438-1444.

Salloway, S., Mermel, L. A., Seamans, M., Aspinall, G. O., Shin, J. E. N., Kurjanczyk, L. A. \& Penner, J. L. (1996). Miller-Fisher syndrome associated with Campylobacter jejuni bearing lipopolysaccharide molecules that mimic human ganglioside GD3. Infect Immun 64, 2945-2949.

Sambrook, J., Fritsch, E. F. \& Maniatis, T. (1989). Molecular Cloning: a Laboratory Manual, 2nd edn. Cold Spring Harbor, NY: Cold Spring Harbor Laboratory.
Schnaitman, C. A. \& Klena, J. D. (1993). Genetics of lipopolysaccharide biosynthesis in enteric bacteria. Microbiol Rev 57, $655-682$.

Schwerer, B., Neisser, A., Polt, R. J., Bernheimer, H. \& Moran, A. P. (1995). Antibody cross-reactivities between gangliosides and lipopolysaccharides of Campylobacter jejuni serotypes associated with Guillain-Barré syndrome. J Endotoxin Res 2, 395-403.

Sprott, G. D., Koval, S. F. \& Schnaitman, C. A. (1994). Cell fractionation. In Methods for General and Molecular Bacteriology, pp. 72-103. Edited by P. Gerhardt, R. G. E. Murray, W. A. Wood and N. R. Krieg. Washington, DC: American Society for Microbiology.

Stroeher, U. H., Karageorgos, L. E., Brown, M. H., Morona, R. \& Manning, P. A. (1995). A putative pathway for perosamine biosynthesis is the first function encoded within the $r f b$ region of Vibrio cholerae O1. Gene 166, 33-42.

Trieucuot, P., Gerbaud, G., Lambert, T. \& Courvalin, P. (1985). In vivo transfer of genetic information between Gram-positive and Gram-negative bacteria. EMBO J 4, 3583-3587.

Tsai, C.-M. \& Frasch, C. E. (1982). A sensitive silver stain for detecting lipopolysaccharides in polyacrylamide gels. Anal Biochem 119, 115-119.

Wang, Y. \& Taylor, D. E. (1990). Chloramphenicol resistance in Campylobacter coli-nucleotide sequence, expression and cloning vector construction. Gene 94, 23-28.

Wassenaar, T. M., Fry, B. N. \& van der Zeijst, B. A. M. (1993), Genetic manipulation of Campylobacter: evaluation of natural transformation and electro-transformation. Gene 132, 131-135.

Whitfield, C., Amor, P. A. \& Köplin, R. (1997). Modulation of the surface architecture of Gram-negative bacteria by the action of surface polymer:lipid A-core ligase and by determinants of polymer chain length. Mol Microbiol 23, 629-638.

Wren, B. W., Henderson, J. \& Ketley, J. M. (1994). A PCR-based strategy for the rapid construction of defined bacterial deletion mutants. Biotechniques 16, 994-996.

Yanisch-Perron, C., Vieira, J. \& Messing, J. (1985). Improved M13 phage cloning vectors and host strains: nucleotide sequences of the M13mp18 and pUC19 vectors. Gene 33, 103-119.

Yao, R., Alm, R. A., Trust, T. J. \& Guerry, P. (1993). Construction of new Campylobacter cloning vectors and a new mutational cat cassette. Gene 130, 127-130.

Yoshida, S., Ohya, Y., Nakano, A. \& Anraku, Y. (1995). STT3, a novel essential gene related to the PKC1/STT1 protein kinase pathway, is involved in protein glycosylation in yeast. Gene 164, 167-172.

Received 14 August 1998; revised 12 October 1998; accepted 28 October 1998. 